Article

\title{
Developing a Building Fire Information Management System Based on 3D Object Visualization
}

\author{
Suhyun Jung ${ }^{1}$, Hee Sung Cha ${ }^{1, *}$ and Shaohua Jiang ${ }^{2}$ \\ 1 Department of Architectural Engineering, Ajou University, Suwon 16499, Korea; suhyun0567@ajou.ac.kr \\ 2 Department of Construction Management, Dalian University of Technology, Dalian 116024, China; \\ shjiang@dlut.edu.cn \\ * Correspondence: hscha@ajou.ac.kr; Tel.: +82-31-219-2508
}

Received: 18 December 2019; Accepted: 21 January 2020; Published: 22 January 2020

\begin{abstract}
In a building fire disaster, a variety of information on hazardous factors is crucial for emergency responders, facility managers, and rescue teams. Inadequate information management limits the accuracy and speed of fire rescue activities. Furthermore, a poor decision-making process, which is solely dependent on the experiences of emergency responders, negatively affects the fire response activities. Building information modeling (BIM) enables the sharing of locations of critical elements and key information necessary for effective decision-making on disaster prevention. However, it is non-trivial to integrate and link the relevant information generated during the life cycle of the building. In particular, the information requirements for building fires should be retrieved in the BIM software because most of them have spatial characteristics. This paper proposes a prototype system for a building's fire information management using three-dimensional (3D) visualization by deriving the relevant information required for mitigating building fire disasters. The proposed system (i.e., Building Fire Information Management System (BFIMS)) automatically provides reliable fire-related information through a computerized and systematic approach in conjunction with a BIM tool. It enables emergency responders to intuitively identify the location data of indoor facilities with its pertinent information based on 3D objects. Through scenario-based applications, the system has effectively demonstrated that it has contributed to an improvement of rapid access to relevant information.
\end{abstract}

Keywords: building information modeling (BIM); fire disaster; facility management

\section{Introduction}

More than $66 \%$ (28,012 cases) of the 42,337 fires reported in 2018 in Korea occurred in buildings and other structures. The highest proportion of fires $(12,376$ cases or $44.2 \%)$ was caused by "carelessness," followed by "electrical factors" (10,469 cases or 30.15\%). In addition, more than $78.5 \%$ of the 12,635 "severe hazardous" cases were exacerbated by "rapid burning of combustible materials" (45\%) and "delay in fire recognition and reporting" (33.5\%). In particular, the most serious cases of building fires were caused by insufficient safety management facilities and inspection systems, malfunctioning of critical firefighting facilities, or insufficient fire response manuals and interventions [1].

These statistical data indicate the importance of fire disaster prevention and response management in buildings to minimize damage due to fire events because it is difficult to predict the incidence of building fires. In particular, these data highlight the critical need for management and inspection of fire safety facilities, and information about the presence of hazardous and harmful substances present in a building should be obtained in advance to enable the preparation of an adequate fire emergency response. In other words, the data point to the need for a series of integrated information management systems that can not only facilitate prevention but also advise about the steps to be 
taken after responding to a fire. However, the current fire disaster management system focuses on the performance inspection of newly constructed buildings and the temporary restoration of existing buildings alone [2].

To deal effectively with building fires, it is crucial to support and respond to fire sites accurately and rapidly in the early stages [3]. The first emergency responders, such as building managers, firefighters, rescuers, and other trained members, should be aware of all aspects of the situation to be able to analyze all information pertaining to the fire site, including the internal structures, facilities, and site-specific risk factors, and make the best decisions under the given circumstances [4]. However, the current fire response method is problematic in that the large amount of distributed information is not transmitted accurately and quickly in the event of a fire incident [2]. Rather, it is likely to transmit inaccurate information from a chaotic fire site. It is also important to collect information in a timely manner, which may prevent secondary damage and property loss [5]. Although the related information requests may be sent to the facility manager, information management in the operation and maintenance $(\mathrm{O} \& \mathrm{M})$ stage is not carried out automatically. As a result, it is difficult to share information quickly, and the accuracy with which information is collected is limited owing to inconsistencies between the building drawings and the actual buildings, as well as the lack of location data for indoor facilities. Further, subjective judgment, which comprises the experiences of fire responders, is common, and deteriorates the safety of fire response activities. Therefore, first emergency responders should be provided with accurate location data of indoor spaces and facilities [6], and the related information needs to be integrated and maintained in the O\&M stage to facilitate easy acquisition of the relevant information [7].

Recently, building information modeling (BIM) is widely adopted as a management tool that can share important information among project stakeholders by creating three-dimensional (3D) object models [8]. BIM is proposed as a powerful solution to integrate and link the information generated during the O\&M stage to enable the sharing of important information at building fire sites. It is necessary to address how fire response information requirements can be managed in advance in the O\&M stage. In this context, the purpose of this study was to develop a building fire information management system (i.e., Building Fire Information Management System (BFIMS) that can rapidly locate and collect critical information by visualizing these requirements for first emergency responders at building fire sites.

\section{Background}

Building fire safety should be managed as part of overall disaster control or mitigation measures and requires an integrated management system [9]. In particular, unlike daily-use convenience facilities, it is important to maintain fire protection facilities on a routine basis because it is difficult to detect any functional failure without the occurrence of an emergency [10]. Facility managers, who are generally responsible for supporting buildings and related services, manage information and knowledge (i.e., financial, human, and physical resources) for strategic building operations and maintenance [11]. Above all, records of O\&M work history and technical documents, such as building drawings, guidelines, and manuals, are important assets for O\&M work. Throughout the digitalization and computerization process, the availability and accessibility of information can be improved sharply [12]. The conventional computer-aided facility management (CAFM) involves documentation, information provision and classification, and monitoring functions related to O\&M tasks [13]. The amalgamation of CAFM and BIM tools is advantageous in that it can identify the location of the building components and provide real-time information relevant to $\mathrm{O} \& \mathrm{M}$ via 3D object models containing large amounts of physical information. In emergencies, BIM-based facility management systems can access data in real time using BIM, enabling emergency responders to identify potential countermeasures and risk factors [14]. In spite of these advantages, in practice, two-dimensional (2D) computer-aided design (CAD) drawings, spreadsheets, or web-based information systems, all of which may store crucial information, are seldom interlinked in an effective way. 
In addition, even buildings with their own respective CAFMs use them in management tasks primarily to optimize the building's operation cost. Thus, the information preparation and management for various disaster response activities are somewhat incidental. The absence of required information reduces the speed of fire responses and threatens the safety of emergency responders. Therefore, to easily obtain relevant information for effective building fire response, firefighting, and disaster prevention-related work, maintenance information should be integrated and managed in the O\&M stage. In addition, in terms of information usability, an instant information output is required for each building space and internal facility. To ensure reliable information management, it is necessary to verify the quality of each data set, and data standardization should be performed to enhance the quality of information management [15]. Therefore, the facility manager can benefit from computerizing the information required in the fire response and continuously updating the changes during the building's life cycle [16].

\subsection{BIM for Fire Disaster Management Systems}

BIM is increasingly being employed to collect and analyze data from various research fields. The combination of computer technology, fire and safety management, facilities, and equipment has become a new trend [17]. When introducing BIM into the field of firefighting and disaster prevention, it is possible to share locations and important information pertaining to emergency decision making at fire sites in connection with the information generated in the O\&M stage [18,19]. Most of the requirements for developing a fire response have spatial characteristics; therefore, they are stored in the BIM, which allows easy information access and use [14]. Wang et al. [7] proposed a BIM-based integrated system consisting of evacuation analysis and evaluation, evacuation route planning, safety education, and equipment maintenance modules. This system can be used in conjunction with a fire dynamics simulator to analyze fire safety and store information that supports safety management in web-based modules. Recognizing the limitation of CAD models in terms of urban disaster prevention, Isikdage et al. [20] proposed a model that combines the geospatial information of buildings and cities using the geographic information system and BIM. Cheng et al. [21] conducted a study on an integrated system that can be used continuously for fire prevention during the countermeasure stages using BIM and a wireless sensor network. The proposed system can display a fire situation and an occupant's location data on a screen using real-time monitoring, and it can provide bidirectional route guidance between an occupant and a rescuer using mobile interworking and a light-emitting diode guiding device.

The above studies utilized BIM as a platform for collecting real-time information, and also provided various functions, such as real-time monitoring, tracking of an occupant's position, and simulation analysis, in consideration of specific factors by linking other software or integrating sensors. However, this methodology has limitations in that it cannot actively utilize the object data of the building as required by emergency responders. In addition, they are limited with respect to system development for integrated information management of requirements, which are classified without reflecting their linkages and vary depending on the users of the information. The absence of information management with regard to the internal facilities hampers the active utilization of the object data, which is the greatest advantage of the BIM. Some studies made attempts to store and utilize object data through the BIM, but they only considered the property information of the materials affected by the fire, the physical characteristics (e.g., location and capacity of the facility), and management status (e.g., inspection history and operation status). They failed to report on the technological aspects of employing information technology integration as a method for collecting and analyzing the real-time information generated at a fire response site. Thus, in the O\&M stage, management information on buildings and related fire response information, such as that pertaining to firefighting facilities, should be complemented by an information management system that can manage and preserve them in advance. 


\subsection{Data Management for Fire Disaster Prevention}

Emergency responders often receive conflicting information at fire sites. As they should be able to accurately share and communicate reliable information in the shortest time, the quality of data collection is paramount [15]. To achieve this, a common platform should be used, and a standardized information requirement should be analyzed to establish a system database. Such a system can provide a recent status of relevant information needed for emergency responders (who are the information users). In particular, because the integrated information based on collaborative processes among emergency responders is very important [18], a common and standardized information system should be established.

Nunavath et al. [4] identified the information structure needed for firefighting teams during a search-and-rescue operation on a university campus, and using the unified modeling language (UML) model, they employed the items as useful tools for communicating with end users. In this study, they classified the general information about the university building, risk factors in the building, personal and family details, the cause and extent of the fire, and resource information about the building. Li et al. [5] classified details about the rescue team before and after arrival at the site using scenario techniques to define the required information according to the response process at the fire site. By performing one-on-one interviews with the rescue team, it was determined that they used the card game method to become a virtual player and derive necessary data according to the response process. Chen et al. [22] proposed a data model that can be used for fire response from a management viewpoint. They classified the activity into sub-activities according to the rescue response process on and off the site to establish a comprehensive classification information structure for fire response. Lee et al. [23] proposed an integrated intelligent urban facilities management approach for real-time emergency response. They attempted to integrate facility information by including a common database, facility database, and 3D geospatial database using sensor information.

Thus, there have been a number of attempts to combine facility management information in the O\&M stage for effective emergency response data management. However, it is difficult to apply the information requirements derived from the previous studies as an integrated system in terms of data sharing and management because the pieces of information differ according to the methodologies or users, and they are classified without reflecting the relationships in the communication flow between emergency responders. In other words, additional complementary pieces of information that can be linked to each other in terms of information sharing are required. Therefore, it is necessary for the facility manager to integrate the pieces of information required for first emergency responders, such as the firefighting or rescue team, so that they may perform response activities directly at the fire site, and to manage them appropriately in the O\&M stage.

\section{Methodology}

This study defines an information structure in conjunction with 3D object model for fire disaster management using BIM software, and develops a BFIMS system prototype that intuitively visualizes the information requirements at building fire response sites. To achieve the purpose of this research, the following three steps were conducted. First, the information requirements to be utilized directly or indirectly by emergency responders were derived based on previous studies related to fire disasters. Based on the derived requirements, the UML was used to establish the data structure and define the relationships among the data. Second, the Sketchup software and the programming language Ruby were used to develop a BFIMS that can intuitively identify location data and detailed information of the building space as well as internal facilities. Finally, the scenario-based case study project was applied to verify the effectiveness of the proposed system, followed by in-depth interviews with experts and practitioners. 


\section{Prototype Design of the BFIMS}

\subsection{Information Requirements}

In complex and chaotic building fire situations, it is important for emergency responders to be able to collect accurate and reliable information in the shortest time, and to analyze the situation by using all available information pertaining to the site [6]. Therefore, sufficient information should be provided in the event of fire disasters involving buildings, and information reliability should be guaranteed by performing regular information management and inspection.

An information management system supports situational awareness by providing a large amount of on-site information to the site commander promptly and accurately, thus guaranteeing the reliability of the information by combining the relevant details and incorporating them into a database [24]. These information requirements were selected only for the building fire prevention and response stages for issues that were mentioned repeatedly in the classification structure proposed by previous studies, namely general information about the building, internal building information, installed facilities and equipment, and real-time fire information. The authors identified the information requirements at the building fire prevention and response stages by carrying out interviews with practitioners (e.g., building managers, fire fighters, and other rescuers.).

As depicted in Figure 1, classification criteria for information requirements related to building fire safety activities were categorized as static information. They included the building type, management history, and storage locations for dangerous property that existed before the occurrence of a fire disaster, as well as dynamic (situational) information, which is generated and collected in real time [6]. Static (non-situational) information can be computerized via collection at the O\&M stage in the system in advance. In particular, most of the information requirements have spatial characteristics. While constructing an information management system that supports information transfer through continuous data management, these requirements were defined only for static information. For the purpose of this research, the static (non-situational) information breakdown structure was established, as provided in Table 1.

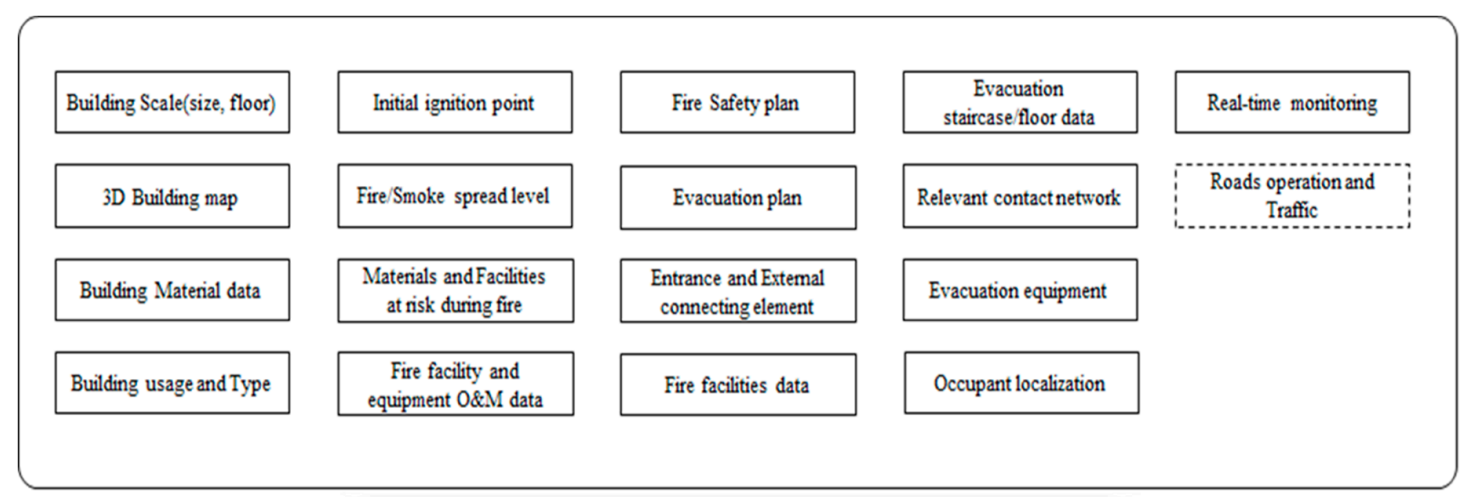

Categorizing
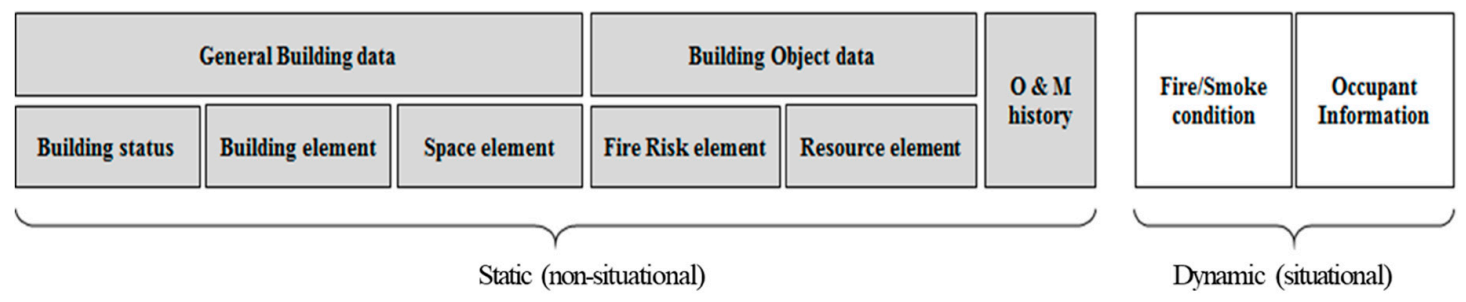

Figure 1. Categorization of the data structure based on the literature review. 
Table 1. Static (non-situational) information breakdown structure for Building Fire Information Management System (BFIMS).

\begin{tabular}{|c|c|c|c|c|}
\hline Level 1 & Level 2 & Level 3 & Description & Example \\
\hline \multirow{11}{*}{$\begin{array}{l}\text { Physical } \\
\text { information }\end{array}$} & \multirow{5}{*}{$\begin{array}{c}\text { General } \\
\text { building data }\end{array}$} & $\begin{array}{l}\text { Building } \\
\text { status }\end{array}$ & $\begin{array}{l}\text { Building status: General } \\
\text { information without forms }\end{array}$ & $\begin{array}{l}\text { Building name, address, main } \\
\text { usage, building structure and } \\
\text { scale (number of floors and area), } \\
\text { contact network }\end{array}$ \\
\hline & & $\begin{array}{l}\text { Building } \\
\text { element }\end{array}$ & $\begin{array}{l}\text { Building outline composed of } \\
\text { structural and non-structural } \\
\text { elements that can be used in } \\
\text { fire response }\end{array}$ & $\begin{array}{l}\text { Structural elements: slabs, walls, } \\
\text { columns, etc. } \\
\text { Non-structural elements: doors, } \\
\text { window, stairs, etc. }\end{array}$ \\
\hline & & \multirow{3}{*}{$\begin{array}{l}\text { Space } \\
\text { element }\end{array}$} & Spatial data & Room usage, location, materials \\
\hline & & & Vertical flow data & $\begin{array}{l}\text { Location of general stairs and } \\
\text { elevators, escalators, emergency } \\
\text { stairs and elevator }\end{array}$ \\
\hline & & & Externally connected elements & $\begin{array}{l}\text { Main entrance, exits, rooftop, } \\
\text { external connection zone }\end{array}$ \\
\hline & \multirow{6}{*}{$\begin{array}{l}\text { Building } \\
\text { object data }\end{array}$} & $\begin{array}{l}\text { Fire risk } \\
\text { element }\end{array}$ & $\begin{array}{l}\text { Facility/area to be checked and } \\
\text { responded to in case of fire event }\end{array}$ & $\begin{array}{l}\text { Location and impact of areas } \\
\text { vulnerable to fire; hazardous } \\
\text { materials; facilities' locations, } \\
\text { types, quantities }\end{array}$ \\
\hline & & \multirow{5}{*}{$\begin{array}{l}\text { Resource } \\
\text { element }\end{array}$} & Fire extinguishing facilities & $\begin{array}{l}\text { Location and status (type and } \\
\text { quantity) of indoor/outdoor fire } \\
\text { hydrants, fire extinguishers, etc. }\end{array}$ \\
\hline & & & Firefighting activity facilities & $\begin{array}{l}\text { Locations and statuses (types and } \\
\text { quantities) of connected } \\
\text { sprinklers, water pipe connections } \\
\text { and facilities, etc. }\end{array}$ \\
\hline & & & Firefighting water facilities & Location, capacity, quantity, type \\
\hline & & & Evacuation and rescue facilities & $\begin{array}{l}\text { Location and status (type and } \\
\text { quantity) of evacuation } \\
\text { equipment (e.g., evacuation } \\
\text { ladders and rescue lifts) and } \\
\text { lifesaving equipment (e.g., air } \\
\text { respirators and heat shields) }\end{array}$ \\
\hline & & & Fire warning facilities & $\begin{array}{l}\text { Location and status of operation } \\
\text { (fire detection, smoke detection, } \\
\text { sensors, etc.) }\end{array}$ \\
\hline \multirow{2}{*}{\multicolumn{3}{|c|}{ ManagementinformationO\&M history }} & Fire management personnel data & $\begin{array}{l}\text { Responsible members' ID, name, } \\
\text { role, contact data, and jurisdiction }\end{array}$ \\
\hline & & & $\begin{array}{l}\text { Maintenance history of } \\
\text { physical information }\end{array}$ & $\begin{array}{l}\text { Work details, including whether } \\
\text { the facility is operational, updated } \\
\text { data, and manager }\end{array}$ \\
\hline
\end{tabular}

UML, an object-oriented modeling language, is a useful tool and considered as a standard tool in developing a database structure in many fields [25]. A class diagram (one of the UML diagrams) illustrates an overview of the system by showing the relationships among the classes. Relationships between objects in a particular application environment and semantically responsible objects can be depicted in this manner. The object properties are specified in the class box, and the relationships between the objects are determined according to line types.

In this study, the attribute data for each object are defined as the type. For instance, the building object data defined in Table 1 are categorized as types. They include the fire risk elements and resource elements that can be used in building fire response. The resource elements are divided into fire extinguishing facilities, firefighting activity facilities, firefighting water facilities, evacuation and rescue facilities, and fire warning facilities. Each object data is a series of component data, including location data and a detailed description about the indoors of the building. The component type is 
used to visualize the location data more intuitively by specifying color by type. General information, which includes the component type and component data, is represented by 3D object data in association with the building shape model together with the management information.

This enables intuitive location data to be collected, and reliable information can be provided by managing O\&M information according to the object. Simultaneously, it is necessary to define additional types so that the flexibility of information management can be guaranteed according to the user's convenience. For the purpose of this study, an UML diagram was constructed as a conceptual data model for BFIMS, as depicted in Figure 2.

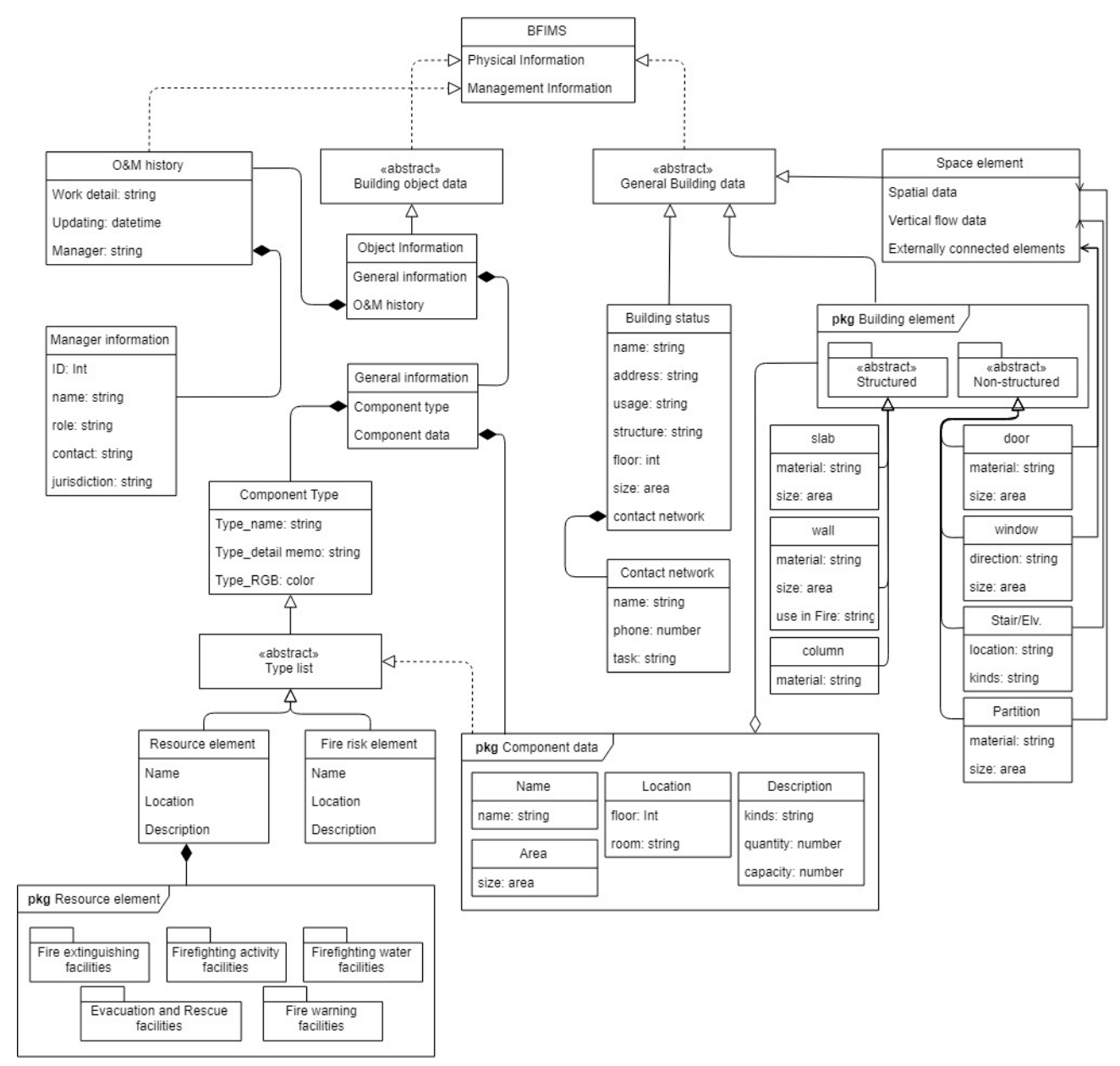

Figure 2. Unified Modeling Language (UML) diagram of conceptual data model for BFIMS.

\subsection{Design of the BFIMS}

The complexity of a system is determined by the plug-in, user accessibility, and functions through the platform chosen to implement and run the system. Furthermore, in terms of system accessibility, users should generally be able to easily modify and configure the database for changes according to the level of information they can process. In particular, for emergency responders, the system interface should be simple and easy to manage. It is also necessary to guarantee data processing speed by reducing large-capacity information loads [26]. Therefore, the system to be developed should be able to extract only the minimum level of information requirements for fire response activities.

Sketchup ${ }^{\mathrm{TM}}$, a conceptual 3D modeling tool, has been unsuitable for complicated building models. However, it is one of the easiest modeling programs for non-professionals to use in that it is useful for quickly constructing approximate mass models. It also requires less system storage capacity compared to other BIM software and, therefore, it can improve data access speed. Sketchup has an 
easy-to-follow interface and an extension (or plug-in) functionality, which can be applied to a variety of applications [27]. Further, it is easily integrated with Google Earth, making it advantageous to apply the extended concept to future urban disaster management. Sketchup is generally used as a schematic design tool in the earlier stages [28].

As a plug-in system, BFIMS was developed via Sketchup software and can further be expandable as a BIM model. The system can be installed as an add-on program to Sketchup. Ruby, which is the default language for Sketchup, was adopted as a programming language for the system.

The Sketchup plug-in program used in this study is named BFIMS. It is a system prototype for managing information that can be used in the maintenance phase for fire safety and in the fire emergency phase for fire control. As seen in Figure 3, the facility manager installs the BFIMS into the Sketchup, which contains a 3D object model with building components. Based on the information structure provided in the previous section (see Table 1), the type is determined. In this stage, any specified object data, including building components, are also stored into the system. When changes are made in the maintenance stage, the stored data are updated using the modification algorithm. In addition, visualization in color designated by the type is possible. The position of the component (object) belonging to each type in the $3 \mathrm{D}$ environment is obtained. The necessary information can be classified according to the corresponding procedure by outputting the details.

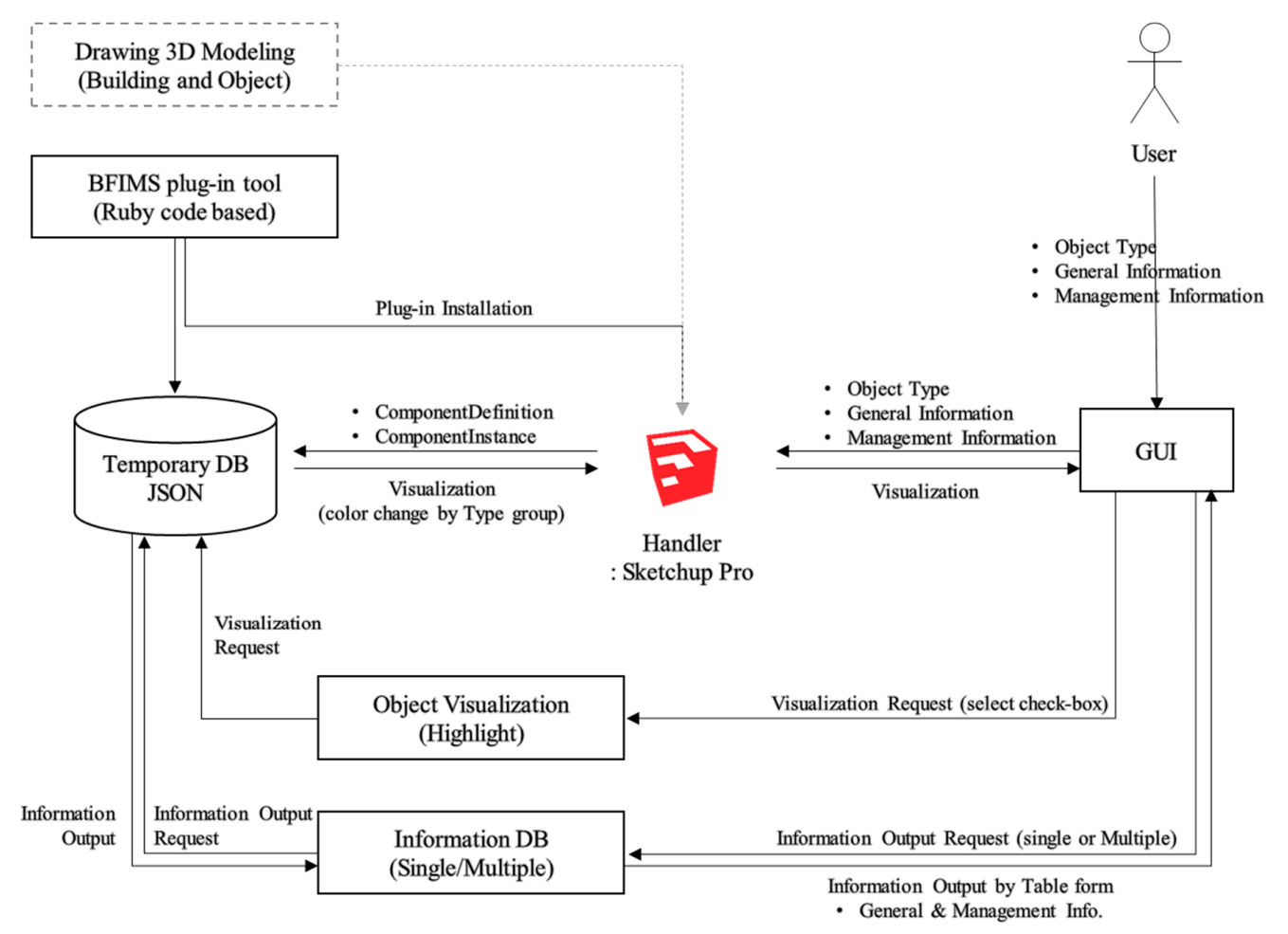

Figure 3. BFIMS architecture.

To construct a database of the 3D object, the authors developed a building model in the Sketchup environment via BFIMS. The model view is in a mass form to improve the data processing speed. The user inputs the object type as well as physical and maintenance information using the graphical user interface and the plug-in. The type information linked with each object and each relevant information are encoded and stored in Javascript Object Notation (JSON) in the attribute of the model. At this time, the type information given to the object is stored in the ComponentDefinition entity, and the information given with regard to each object is stored in the ComponentInstance entity. Sketchup visualizes the single or grouped multi-object information selected by the user. As a result of the data processing, it can also retrieve the detailed information in a real-time basis. 


\section{Prototype Development and Scenario Analysis}

\subsection{Prototype Implementation of the BFIMS}

The BFIMS consists of four modules: (1) "Management" module for setting by type; (2) "object" module for object data input; (3) "information" module; and (4) "report" module for object data output (see Figure 4a). The BFIMS uses graphical elements to convey information to end users instantly (see Figure 4 b). In the object module, a particular type is set as a metadata for grouping and visualizing individual object information. The type is interlined with the values used in JSON (lines 34-49 in Figure 5) by designating the name and describing the type and the colors for visual representation of the grouped objects (lines 7-23 in Figure 5). It is grouped by the type list in the checkbox format. The type consists of fire risk elements and resource elements as depicted in Figure 4.

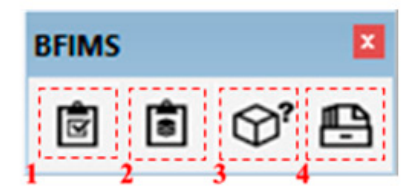

(a)

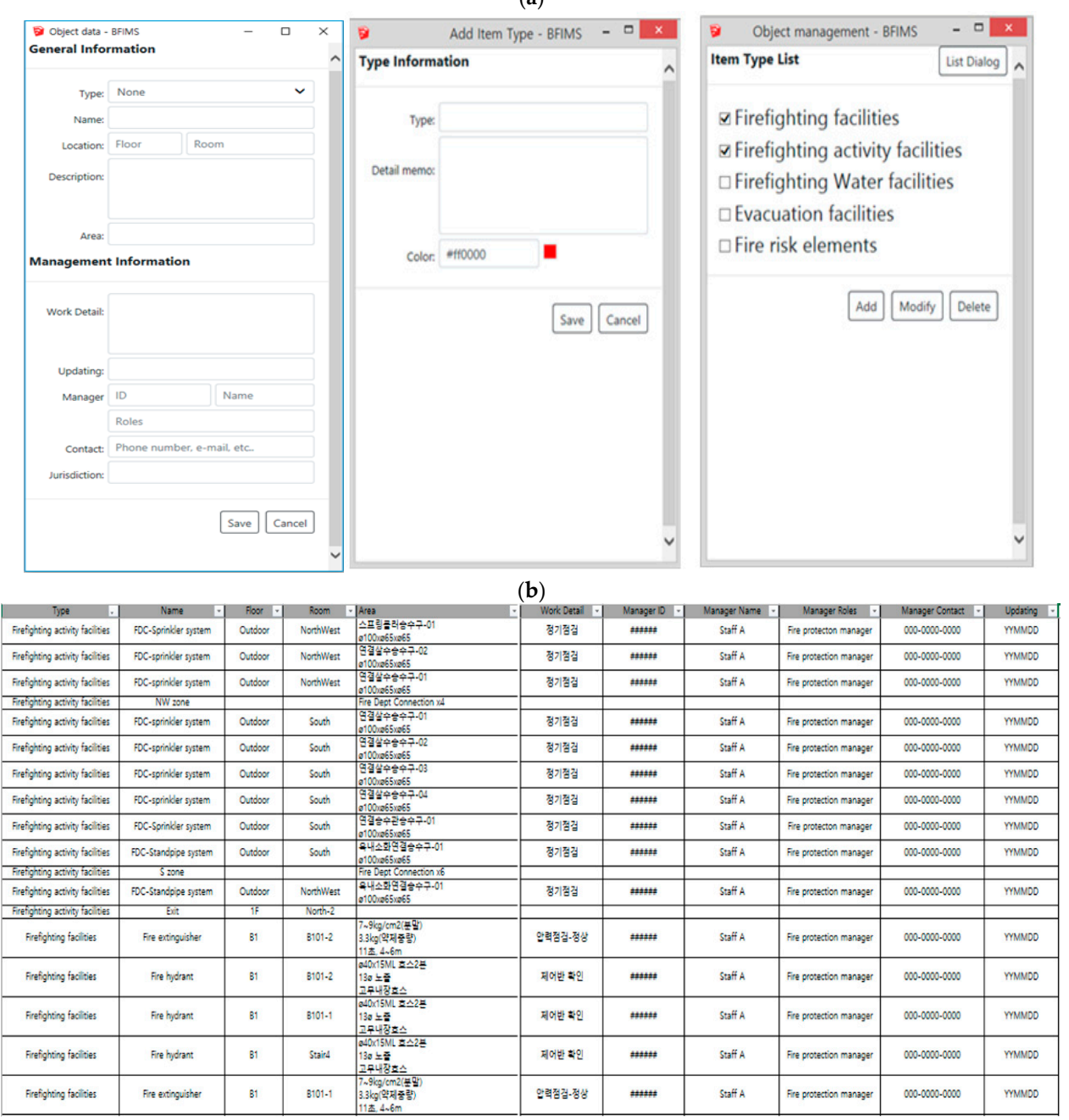

(c)

Figure 4. Examples of the BFIMS screenshot. (a) Graphic User Interface (GUI) module icons in BFIMS (1: Management; 2: Object; 3: Information; 4: Report); (b) GUI screenshots in BFIMS (left: type input; center: type selection; right: data input); (c) Fire facilities data derived from BFIMS 


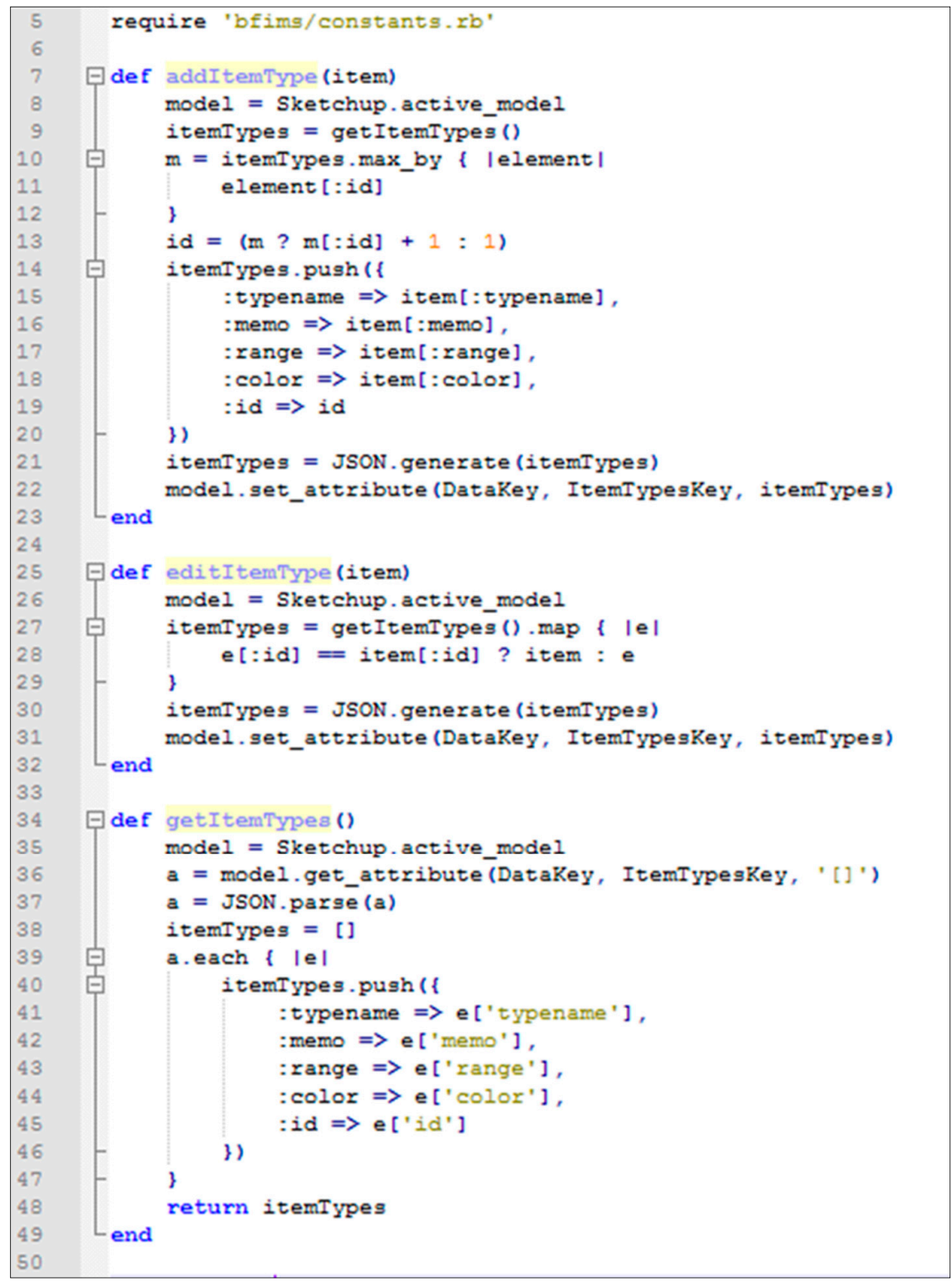

Figure 5. System code: data input. 
Typically, the object model created in Sketchup can be stored such that each component has its own location and physical information, but there are limits to the storage of user-recognizable location data and maintenance information. In the "object" module, the user creates a particular object as a Sketchup component, and then sets the category to which each object belongs by selecting the type defined in the "management" module as well as the relevant attribute data, such as location and maintenance history data (lines 16-20 in Figure 6). Objects with the selected type can be visualized in the color designated by selecting the check box in the type list, and are classified by type (Figure 7a). In addition, objects that are distinguished by color can be visualized in a 3D environment, which can show instant spatial relationships and their locations.

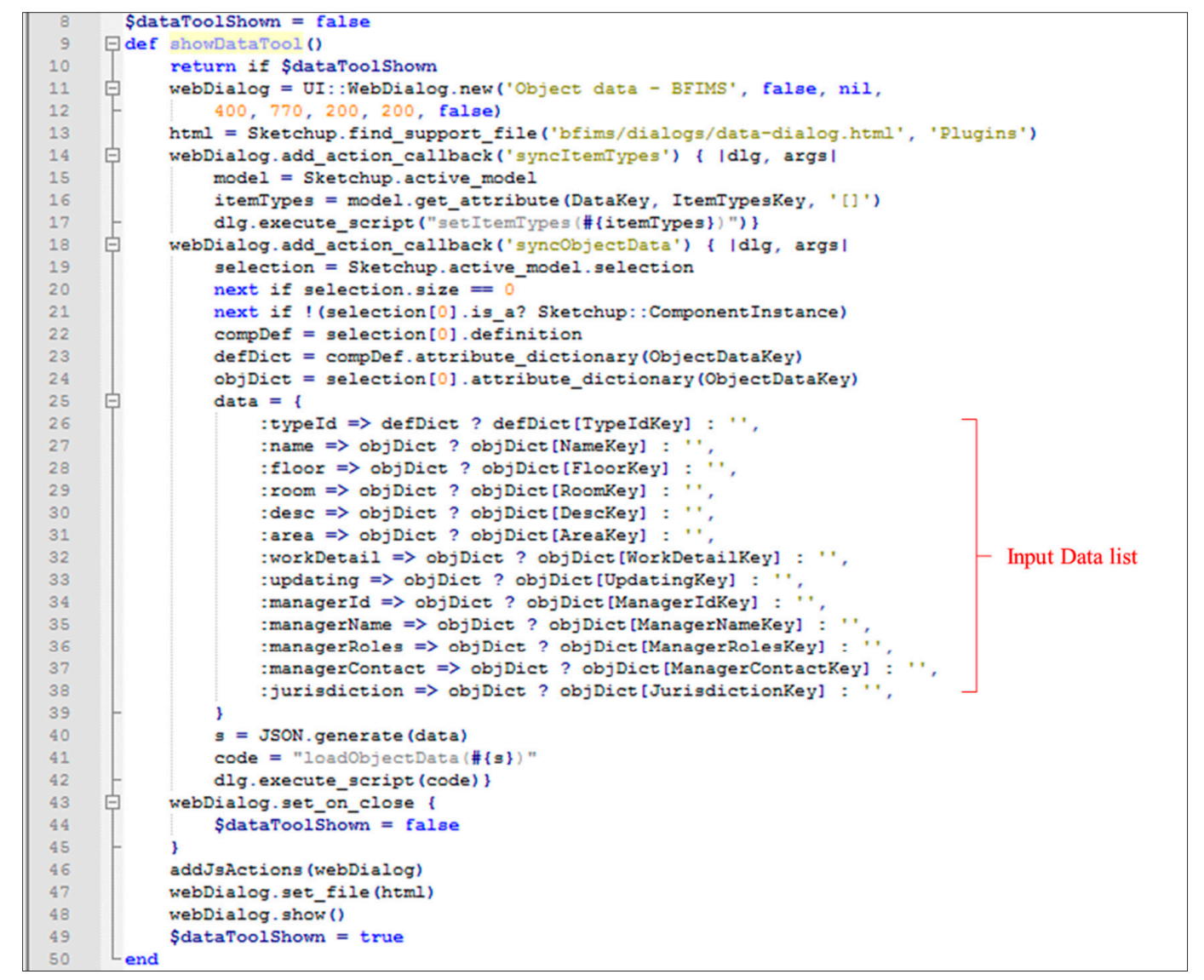

Figure 6. System code: Object data input. 


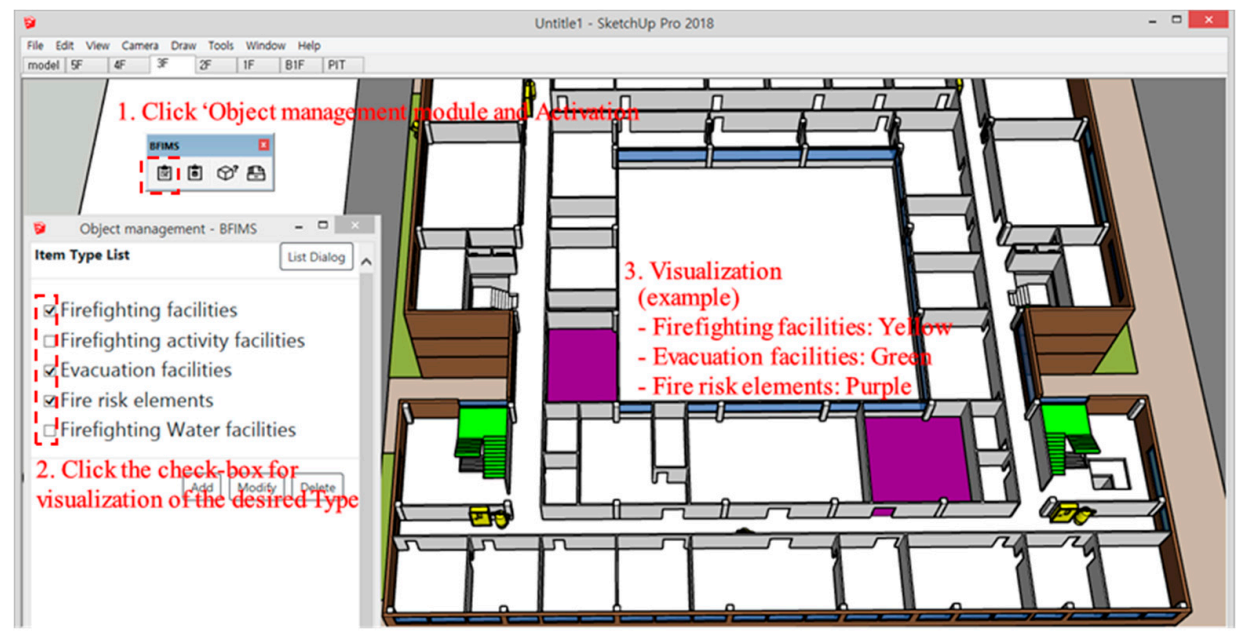

(a)

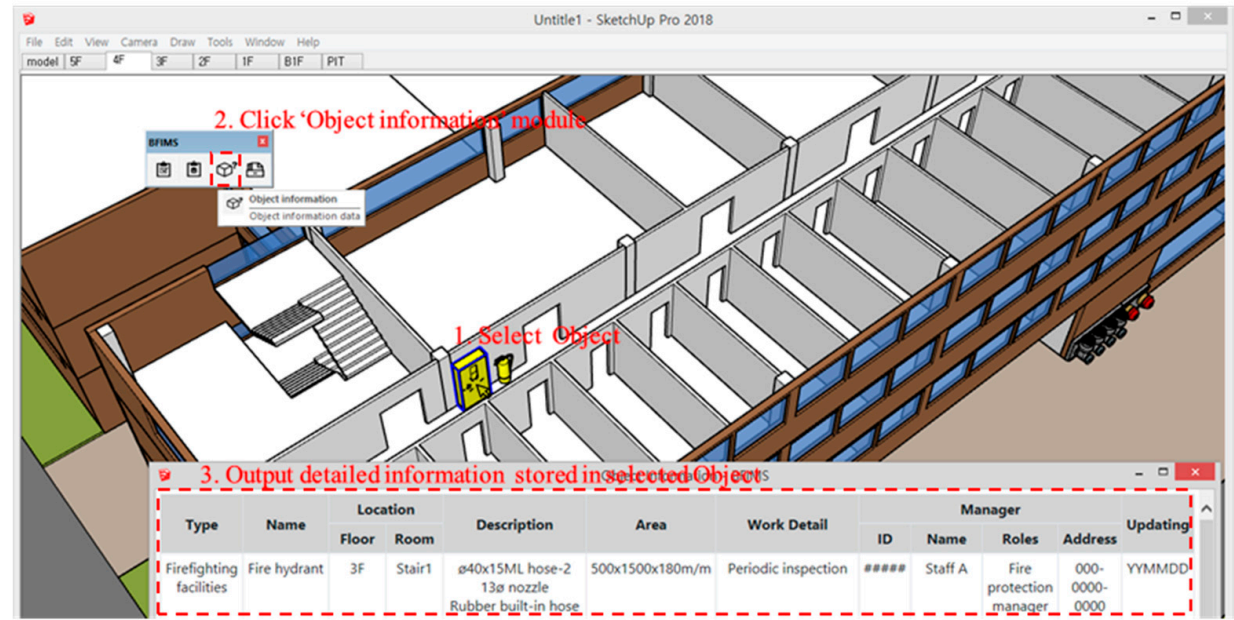

(b)

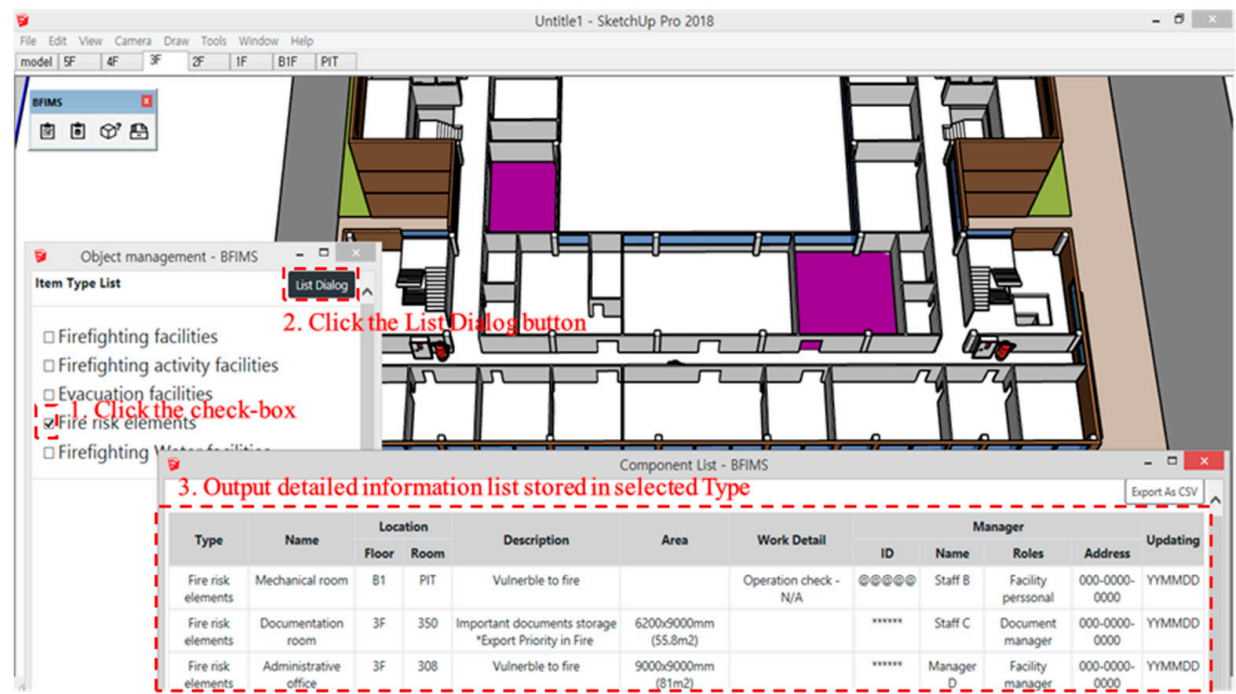

(c)

Figure 7. BFIMS implementation: (a) Object visualization; (b) single object data output; and (c) multiple grouped objects data output.

The "information" module is used to display the defined object information in a tabular form in a single unit (Figure 7b). Moreover, a method exists to display multiple grouped object information by outputting the attribute data pertaining to the objects dependent on the selected types using the list 
dialog in the "management" module (Figure 7c). In the "report" module, attribute data of all objects stored in the "object" module can be generated in a spreadsheet format. They can be exported to an Excel $^{\mathrm{TM}}$ file and saved for additional analysis in the future.

\subsection{Application of the BFIMS}

To verify the proposed system, an imaginary case-study project, a five-story university building, was applied using a scenario-based framework, as depicted in Figure 8.

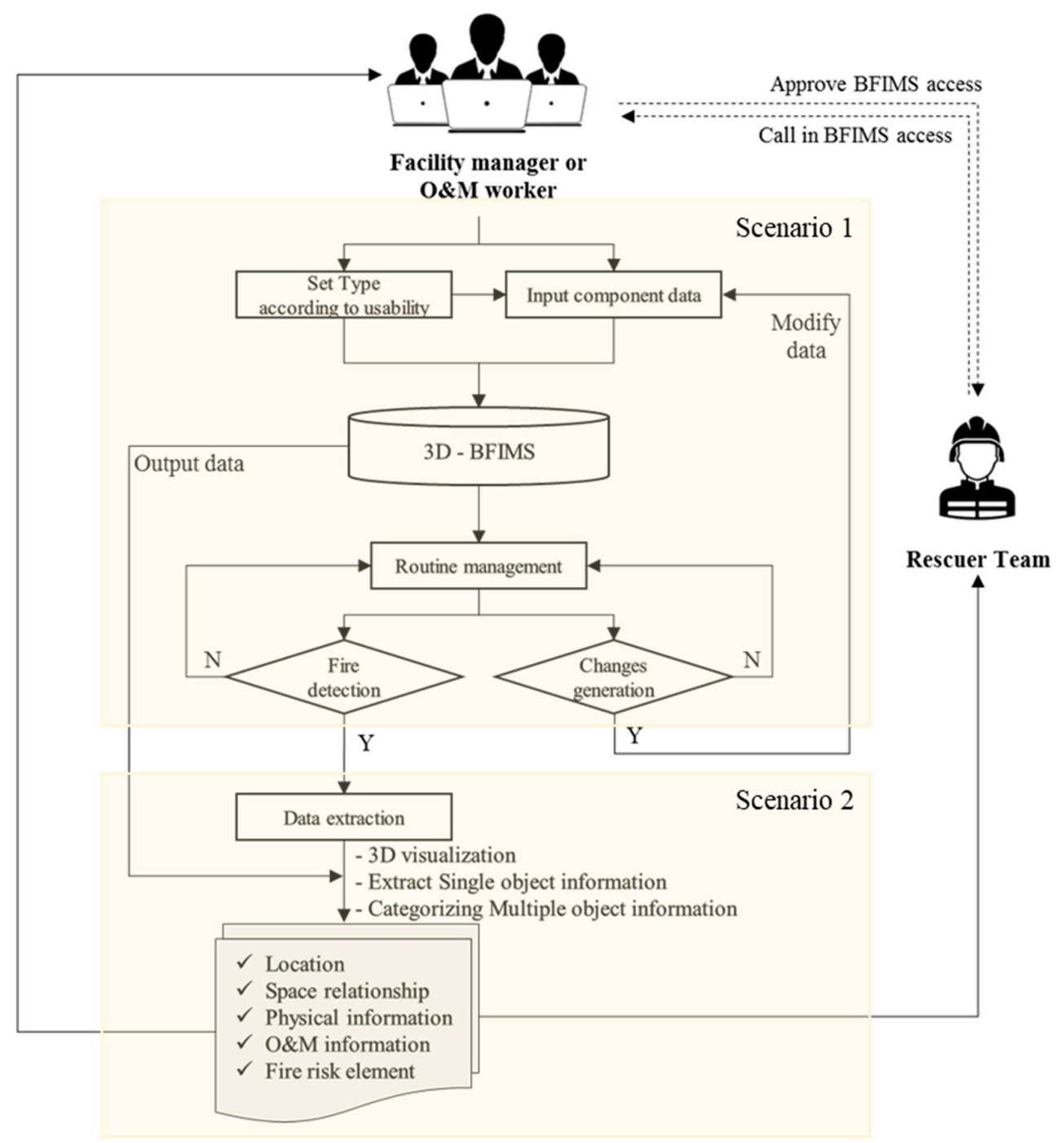

Figure 8. Scenario-based BFIMS application framework.

- Scenario 1: Routine monitoring for facility management

Facility managers or employees regularly inspect the firefighting facilities for fire prevention and preparation. They also manage hazardous materials that are brought into or taken outside the building. The system users can obtain the results in a spreadsheet format as a list of all objects. This information needs to be managed based on the object information stored in the BFIMS database. BFIMS allows them to create checklists to support inspection work items and increase maintenance work productivity. In addition, by managing the detailed information and inspection data of each facility, the manager can use this system to predict the obsolescence of the facility, determine the timing of replacements, and/or enhance the inspection quality. 
During the course of routine monitoring, should changes occur during the life cycle of the building, they can be updated with the BFIMS modification function to ensure up-to-date building information. The visualization of this information is based on 3D objects, which provide intuitive location information to the manager, thereby making inspection and maintenance work more convenient.

- Scenario 2: Emergency control in the case of fire occurrence

When a building fire occurs, facility managers move to the site to determine whether or not the fire is real and take actions according to the emergency manual. They also seek the location of the nearest fire hydrant and activate the fire hydrant transmitter to trigger a fire alarm throughout the building. Then, they guide occupants to escape safely through the evacuation stairs, and remove important documents or items from the building. Furthermore, any disastrous area that may affect the entire building owing to fire should be addressed in advance.

However, this fire control process is solely dependent on the manager's experience and memory, which can lead to delays in response time owing to degraded cognitive abilities during challenging events, such as emergencies. Using the proposed BFIMS, emergency responders can quickly identify the visible locations of fire extinguishing facilities, evacuation facilities, and fire risk element information that need to be used. In other words, detailed information, including location data, can be collected, after which the priority of the initial response can be determined based on this reliable objective information. For example, the manager can identify the location of a fire extinguisher or fire hydrant near the ignition point, raise an alarm, broadcast the situation based on the available resource elements, and attempt to control the fire early.

To improve the effectiveness of the proposed system, this study assumes that emergency responders are given the approval to use the BFIMS so as to share the information. In general, firefighting teams are not familiar with a particular building layout. Therefore, it requires time and effort to analyze the spatial relationship inside the building before arriving at the fire site. With this system, prompt decision making can be achieved even if the visible distance inside the building is limited owing to the spread of flames and smoke. In addition, the model supports optimum route calculations and improves the utilization of the fire prevention resources (e.g., fire hydrants, fire extinguishers, sprinklers, standpipe systems, and fire department connections). Because these resources contain certain information required for the fire response activities, the emergency responders can collect the information quickly and assist strategic decision-making based on the linkages of the information with the surrounding environment. Moreover, the firefighting teams can obtain the information on firefighting water facilities and firefighting activity facilities prior to dispatch so that the amount of equipment and water to be transported can be estimated appropriately. This aspect can improve responsiveness to building fires as the rescuers can utilize the resources of the building itself or request additional support in advance to ensure the speed with which the necessary resources need to be procured.

\subsection{Expert Feedback on the BFIMS Prototype}

The system validation was conducted with experts in building fire disaster. The group of experts included two facility managers (senior manager and practitioner) and two firefighting crew members (crew commander and leading firefighter) with more than 10 years of experience. This focus group interview was conducted to determine how they can effectively identify the location data and relevant information at the case study application project, using the BFIMS. They were also asked about how the accuracy level of the fire-related information can be improved and how they can save time taken to acquire information about the fire site.

In terms of the locations of the building structures and internal facilities, all interviewees replied that 3D models are more powerful than 2D drawings, as the former can easily provide detailed information based on each location. They also responded that the information management of the proposed system can reduce the time and errors in documenting and reporting the building status, 
compared to the conventional (manual) approach. From the perspective of fire fighters, they responded that an effective and efficient fire response strategy can be obtained with the BFIMS applications.

However, the facility managers who maintain and update the system database should input the raw data in a manual basis, thus generating additional work. The feedback indicates that the system should be sophisticated enough to allow automation of data input. Furthermore, they revealed that public sector buildings are less benefited compared with private sector buildings because the facility managers, who usually reside in the building, are already familiar with the building information, given that they regularly and systematically conduct facility inspections with their own respective systems. However, the firefighting crew asserted that BFIMS would be advantageous in reducing the time required for information collection, and prioritizing the rescue activities under the assumption that the system can be shared among the emergency rescuers. In particular, the firefighting crew responded that they would appreciate if the internal location data could be instantly gathered by the proposed system. Additional feedback indicated that the system effectiveness would be improved if the spreading of flames and smoke during a building fire could be indicated in real time. In summary, it is concluded that the new system demonstrates a potential benefit to emergency responders who are currently managing information conventionally (using paper-based documents alone).

\subsection{Limitations of the System Validation and Future Research}

The expert feedback on the proposed system has some limitations in validating the effectiveness of the system. First of all, the number of focus group interviews should be expanded. At the time of writing, the BFIMS has only been pilot-tested in terms of potential benefits of information exchange via the 3D object-based information storage and retrieval process. Second, the two groups (facility manger and firefighters) may require different types of information. As such, the validity should be examined using different usage scenarios. Thirdly, the real case project should be applied to fully verify the impact of the new system. As a pioneering study, the validation results from two scenario-based applications reveal that the current fire disaster management has much to be improved. Rather than scenario-based applications, a real case study project may provide a robust validation in a building fire disaster. In future research, this novel system should be further developed in terms of technological aspects. Mobile devices (tablet PC or smart devices) are commonly used in the industry. So, the system would be much benefited when it is operable in a web-based environment. Additionally, a cloud-server programming can be useful to ensure transmission of BIM data at different stages and connectivity between the 3D model and the data because simultaneous information sharing is critical in building fire control. Finally, the sensor information (e.g., fire, smoke, and flame) should be linked with the system in an automatic way. The real-time collection and sharing of information is critical under the fire situation of a building.

\section{Conclusions}

The urgency and accuracy of information required at an initial fire disaster site are important factors to consider to effectively cope with building fires. First emergency responders should be able to acquire and analyze accurate and detailed information about the indoors of a building to make optimal decisions. This study proposed a system prototype for 3D object visualization-based building fire information management using the Sketchup software. Previous works were reviewed, and interviews were conducted with experts to better understand the sets of key information needed by emergency responders. The main features of the information requirements are the spatial relation and attribute data of the object. The key information for an effective building fire response comprises spatial data and location data. By focusing on these aspects, this study developed a system prototype that first visualizes $3 \mathrm{D}$ buildings and objects according to each type using designated colors to utilize such object information and then outputs the object information.

The proposed information breakdown structure also recognizes that appropriate information should be shared among emergency responders in order for them to cope effectively with fires. It is 
expected that this system can be used as a fundamental source to identify all factors relevant to the integration of information-based facility management and disaster management. The authors contributed to the extension of BIM to fire safety and disaster management by developing an information system based on space and object data. This necessitates digitizing the inspection history and various previously recorded materials (paper-based documents). These improvements in the usability of the information will also translate to more reliable information. In particular, the proposed system improves accessibility to indoor information that is not currently communicated to emergency responders by providing location data and attribute data of the firefighting facilities. Therefore, it is hoped that decision making based on objective information, rather than subjective experiences, would improve building fire safety.

However, the proposed system has some limitations. The scope of the information management system in this study is limited to an after-the-fact approach. In reality, a building fire disaster can be controlled using a preventive maintenance approach. For example, not only the fire disaster facility information but also other various factors (e.g., energy, space layout, and occupants' use) should be incorporated to enhance the fire safety of a building. In addition, it is important to integrate the static and dynamic real-time information generated at fire sites because the information required to construct the database in this study was developed as part of an information system that can gather and store data in advance.

In the future, this system should be extended to serve as an integral disaster management system that is capable of acquiring and analyzing various aspects of both internal and external environments of a building. This would be accomplished by not only obtaining real-time dynamic information through sensing technology integration but also integrating the system with other simulation programs to analyze the diffusion paths of flames and smoke. Moreover, despite the use of a relatively easy-to-use program, the access speed decreases as the number of objects (components) in the 3D model increases. Therefore, future work will investigate possible improvements to the system access speed when using larger amounts of BIM data.

Author Contributions: Conceptualization, S.J. (Suhyun Jung) and H.S.C.; methodology, S.J. (Suhyun Jung) and H.S.C.; software, S.J. (Suhyun Jung); validation, S.J. (Suhyun Jung) and S.J. (Shaohua Jiang); formal analysis, H.S.C.; investigation, S.J. (Shaohua Jiang); resources, S.J. (Suhyun Jung); data curation, S.J. (Suhyun Jung); writing - original draft preparation, S.J. (Suhyun Jung); writing - review and editing, H.S.C. and S.J. (Shaohua Jiang); visualization, S.J. (Suhyun Jung) and H.S.C.; supervision, H.S.C.; project administration, S.J. (Suhyun Jung); funding acquisition, H.S.C. All authors have read and agreed to the published version of the manuscript.

Funding: This research was supported by National Research Foundation of Korea (NRF), grant number 2017R1E1A1A01075266.

Conflicts of Interest: The authors declare no conflict of interest.

\section{References}

1. Kim, J.; Hong, C. A study on the Application Service of 3D BIM-based Disaster Integrated Information System Management for Effective Disaster Response. J. Korea Acad. Ind. Coop. Soc. 2018, 19, 143-150.

2. Nunavath, V.; Prinz, A.; Comes, T. Identifying First Responders Information Needs: Supporting search and rescue operations for fire emergency response. Int. J. Inf. Syst. Crisis Response Manag. (IJISCRAM) 2016, 8, 25-46. [CrossRef]

3. Kiyomoto, S.; Fukushima, K.; Miyake, Y. Design of Categorization Mechanism for Disaster-Information-Gathering System. J. Wirel. Mob. Netw. Ubiquitous Comput. Dependable Appl. 2012, 3, 21-34.

4. Tashakkori, H.; Rajabifard, A.; Kalantari, M. A new 3D indoor outdoor GIS model for indoor emergency response facilitation. Build. Environ. 2015, 89, 170-182. [CrossRef]

5. Li, N.; Yang, Z.; Ghahramani, A.; Becerik-Gerber, B.; Soibelman, L. Situational awareness for supporting building fire emergency response: Information needs, information sources, and implementation requirements. Fire Saf. J. 2014, 63, 17-28. [CrossRef]

6. Dilo, A.; Zlatanova, S. A data model for operational and situational information in emergency response. Appl. Geomat. 2011, 3, 207-218. [CrossRef] 
7. Wang, S.H.; Wang, W.C.; Wang, K.C.; Shih, S.Y. Applying building information modeling to support fire safety management. Autom. Constr. 2015, 59, 158-167. [CrossRef]

8. Davtalab, O. Benefits of Real-Time Data Driven BIM for FM Departments in Operations Control and Maintenance. In Proceedings of the ASCE International Workshop on Computing in Civil Engineering, Seattle, WA, USA, 25-27 June 2017.

9. Ramachandran, G. Fire safety management and risk assessment. Facilities 1999, 17, 363-377. [CrossRef]

10. Chen, H.M.; Wang, Y.H. A 3-dimensional visualized approach for maintenance and management of facilities. Proc. ISARC 2009, 468-475. [CrossRef]

11. Nutt, B. Four competing futures for facility management. Facilities 2000, 18, 124-132. [CrossRef]

12. Pintelon, L.; Preez, N.D.; Puyvelde, F.V. Information technology: Opportunities for maintenance management. J. Qual. Maint. Eng. 1999, 5, 9-24. [CrossRef]

13. Elmualim, A.; Pelumi-Johnson, A. Application of computer-aided facilities management (CAFM) for intelligent buildings operation. Facilities 2009, 27, 421-428. [CrossRef]

14. Becerik-Gerber, B.; Jazizadeh, F.; Li, N.; Calis, G. Application areas and Data Requirements for BIM-enabled Facilities Management. J. Constr. Eng. Manag. 2012, 138, 431-442. [CrossRef]

15. Seppanen, H.; Virrantaus, K. Shared situational awareness and information quality in disaster management. Saf. Sci. 2015, 77, 112-122. [CrossRef]

16. Davies, D.K.; Ilavajhala, S.; Wong, M.M.; Justice, C.O. Fire information for resource management system: Archiving and distributing MODIS active fire data. IEEE Trans. Geosci. Remote Sens. 2008, 47, 72-79. [CrossRef]

17. Shiau, Y.C.; Tsai, Y.Y.; Hsiao, J.Y.; Chang, C.T. Development of Building Fire Control and Management System in BIM Environment. Stud. Inform. Control 2013, 22, 15-24. [CrossRef]

18. Amaro, G.G.; Raimondo, A.; Erba, D.; Ugliotti, F.M. A BIM-based approach supporting fire engineering. In Proceedings of the International Fire Safety Symposium, Naples, Italy, 7-9 June 2017.

19. Abolghasemzadeh, P. A comprehensive method for environmentally sensitive and behavioral microscopic egress analysis in case of fire in buildings. Saf. Sci. 2013, 59, 1-9. [CrossRef]

20. Isikdag, U.; Underwood, J.; Aoudad, G.; Trodd, N. Investigating the Role of Building Information Models as a Part of an Integrated Data Layer: A Fire Response Management Case. Archit. Eng. Des. Manag. 2007, 3 , 124-142. [CrossRef]

21. Cheng, M.Y.; Chiu, K.C.; Hsieh, Y.M.; Yang, I.T.; Chou, J.S.; Wu, Y.W. BIM integrated smart monitoring technique for building fire prevention and disaster relief. Autom. Constr. 2017, 84, 14-30. [CrossRef]

22. Chen, R.; Sharman, R.; Rao, H.R.; Upadhyaya, S.J. Data Model Development for Fire Related Extreme Events: An Activity Theory Approach. MIS Q. 2013, 37, 125-147. [CrossRef]

23. Lee, J.W.; Jeong, Y.W.; Oh, Y.S.; Lee, J.C.; Ahn, N.S.; Lee, J.H.; Yoon, S.H. An integrated approach to intelligent urban facilities management for real-time emergency response. Autom. Constr. 2013, 30, 256-264. [CrossRef]

24. Foltz, S.D.; Brauer, B. Communication, Data Sharing, and Collaboration at the Disaster Site. In Proceedings of the ASCE International Conference on Computing in Civil Engineering, Cancun, Mexico, 12-15 July 2005.

25. Xu, W.; Dilo, A.; Zlatanova, S.; Oosterom, P.V. Modelling emergency response processes: Comparative study on OWL and UML. In Proceedings of the Joint ISCRAM-China, GI4DM Conference, Harbin, China, 4-6 August 2008; pp. 493-504.

26. Fan, H.; Meng, L. A three-step approach of simplifying 3D buildings modeled by CityGML. Int. J. Geogr. Inf. Sci. 2012, 26, 1091-1107. [CrossRef]

27. Schreyer, A.C. Architectural Design with SketchUp: 3D Modeling, Extensions, BIM, Rendering, Making, and Scripting, 2nd ed.; John Wiley \& Sons: Hoboken, NJ, USA, 2015.

28. Choi, B. A Study of the Use of Computer Softwares in Architectural Design Field. Proc. Reg. Assoc. Archit. Inst. Korea 2012, 8, 7-8.

(C) 2020 by the authors. Licensee MDPI, Basel, Switzerland. This article is an open access article distributed under the terms and conditions of the Creative Commons Attribution (CC BY) license (http://creativecommons.org/licenses/by/4.0/). 